\title{
Some Phenomena associated with THE FLOW OF STEAM THROUGH NOZZLES.
}

Paper read before the Institution by A. L. MELLANBY, D.Sc., Honorary Member, Glasgow, on 23rd March, 1922, at Glasgow.

\section{PAPER No. 125.}

Although a Paper dealing with the flow of steam through nozzles may appear, at first sight, to be of little interest to members of this Institution, yet a little consideration will show that a true appreciation of the laws of steam flow may be, in the future, of the greatest use to those engaged in the development and improvement of the locomotive. Even at the present time some locomotives have been already fitted with steam turbines, and it is well known that the possibility of utilising this type of prime mover is being entertained seriously by several locomotive builders in this country. For this reason it was considered that a Paper describing something of what takes place when steam passes through a nozzle would be acceptable to the members of the Institution, and I am hoping, therefore, to interest you by the relation of some of the more recent experimental work that has been done upon this subject in the Royal Technical College, Glasgow. 
It might be thought that the nozzle was a comparatively unimportant part of a turbine, and, if considered from the standpoint of size and cost of manufacture, this opinion would be justified. But when we consider the actual design of a turbine and have to decide how the various parts should be related for maximum economy in working it will be found that the nozzle proportions are those which must first be fixed. At the risk of being tedious let me go over a few elementary points relating to turbine design. The action of a steam turbine depends upon the conversion of the heat energy contained in the steam into kinetic energy. By allowing the steam to pass through suitably shaped nozzles it is made to fall in pressure and temperature and thus to acquire a very high velocity. This high velocity steam is directed towards vanes mounted on drums or wheels, and, by impinging upon these vanes, causes rotation of the shaft. The steam leaves the vanes with a velocity much lower than that at entrance, and the fall of velocity is a measure of the work it has done. The investigation of the laws which determine the efficiency of nozzles under different pressure and temperature conditions has attracted experimenters for many years, but it is only within comparatively recent times that a real appreciation has been obtained of the phenomena involved during the process of dropping from a high to a low pressure. The first serious attention to the subject of nozzle flow seems to have been given in 1867 , when Mr. R. D. Napier, in a series of letters to "The Engineer," described the results of a number of experiments he had made. The feature of Mr. Napier's work which attracted most attention was the fact that the amount of steam passing through an orifice did not depend altogether upon the pressure drop. He showed that when steam passed from a vessel of constant high pressure, through an orifice, into one of lower pressure the steam discharged at first increased as the back pressure was lowered. When the back pressure was equal to about half of the inlet pressure any further lowering produced no effect upon the steam flow, which, so far as could be seen from the measurements he was able to make, remained constant however much lower this back pressure was reduced. The correspondence which resulted from this publication of Napier's work shows that much doubt was felt by some of the readers about the correctness of his statements-a somewhat natural feeling seeing that the results appeared to be contrary to the laws of flow of gases as then accepted. It was not until 1886 that the real interpretation of Napier's results was given by Osborne Reynolds, who, in a theoretical 
investigation, showed that in a nozzle of varying section the velocity of the steam at the section of minimum area was the same as that of sound. From this he demonstrated that, if a gas is passing through an orifice into a region of lower pressure, the minimum pressure at the orifice itself corresponded to that at which the gas speed was equal to the velocity of sound in the gas and that no further lowering of the back pressure could increase the amount of fluid discharged. This critical pressure, at. which the velocity of sound is reached, has a value equal to a little more than half that of the initial pressure, and consequently when the pressure of the receiving reservoir is made lower than this the effect upon the steam flow is unappreciable.

However much we may be impressed by theory, there is always a desire, at least on the part of the engineer, to obtain some confirmatory measurements, and consequently a record of the actual pressures along a nozzle would appear to be desirable. A method of obtaining these pressures, due to Prof. Stodola of Zurich, is shown in Fig. I, where a nozzle will be observed with a search tube passing through it. A small hole in the side of the search tube permits the pressure to be communicated to a gauge, and a reading of the micrometer screw $M$ enables the position of the hole to be located. In carrying out a series of experiments with this apparatus, the admission pressure and temperature and the back pressure conditions under which the nozzle is required to work, are first determined. These are kept as constant as possible during any one test. When a steady condition has been attained the search tube is set so that the small hole is about $\frac{1}{4}$ in. in front of the inlet edge, and a reading of the pressure gauge is then taken. The search tube is then passed along the jet in short steps, and at each step another reading of the gauge is made. The total movement of the search tube is about $I \frac{3}{4}$ ins., and this serves to give readings from $\frac{1}{4}$ in. in front to $\frac{1}{2}$ in. beyond the outlet of the largest nozzle. The travel between readings depends upon the steepness of the pressure curve and may vary from I/ Iooth to I/ Ioth of an inch. Some characteristic curves are shown in Figs. 2, 3 and 4 .

Taking the case of a short convergent nozzle, the curves with constant admission but different back pressures are shown in Fig. 2. For convenience the ordinates are made as pressure ratios-that is, the values of the search tube readings divided by the initial pressure-since it is known that these ratios remain fairly constant although the initial pressure may change. The lowest pressure recorded in the nozzle is just $0.5^{8}$ of the initial pressure (theoretical 0.55 ), 
although the diagram shows that the back pressure in the receiver has been in one case as low as 0.3 , and in another case 0.45 of the initial pressure. When once the back pressure rises above this critical value, the pressure along the nozzle rises simultaneously as shown by the upper curves. With a longer nozzle the curves are as shown in Fig. 3. Here they will be seen to have the same general characteristics as the previous ones, but it should be noted that, at the end of the nozzle, the pressure drops to 0.5 of the initial pressure. This lower pressure is the result of the extra frictional resistance set up by the longer nozzle. It is a point to which special attention has been given by $\mathrm{Mr}$. David Anderson in some researches he is conducting in my laboratory upon rough and smooth nozzles, and I am hoping that he will be able to tell us something about the results he has obtained from this work.

It might be said that it is often desirable to design a nozzle to give greater pressure drops than from some initial pressure to a lower one about 0.55 of that value. In such cases it will be found that the nozzle must be of the convergent divergent form. In designing such a nozzle it is generally assumed that the pressure at the throat (the end of the convergence) will be 0.55 of the initial pressure, and the throat area is fixed by this consideration. The nozzle is then gradually increased in area and the end section is designed to allow for the amount of steam that will pass at the velocity generated by the full drop of pressure. The pressure curves along such a nozzle with different back pressures are shown in Fig. 4. This diagram discloses several points of interest. The most notable feature is the low value of the nozzle throat pressure. It is difficult to see why this pressure should not agree closely with the theoretical value of 0.55 initial pressure, but this expected agreement seems hardly ever to exist. It seems fairly certain that this low value indicates a separation of the jet and the nozzle throats, or, in other words, that there is a slight breakaway of the jet from the nozzle contour. (This point is illustrated by Fig. 5.) The effects of raising the back pressure should also be noticed. This nozzle was designed to reduce the pressure to about 0.19 initial pressure, and in that case the recorded pressure drop along the nozzle is shown as a steadily falling curve. When once the back pressure is above this value, note, however, the amount of recompression in the nozzle. The throat pressure is not affected until the back pressure is about 0.75 of the initial pressure, and at about this particular pressure the amount of recompression is very great. Since the throat pressure 
fixes the amount of steam passing there is no change in the discharge until this high back pressure is reached. This, however, does not mean that the nozzle is working with a constant efficiency. The extensive over-expansion and recompression must entail severe losses, and it is obvious that a nozzle of this type should not be used to work at a back pressure higher than that for which it is designed. This is a fact known to practical designers, who always make the end section somewhat less than that required by theory since they prefer to run the risk of under rather than over-expansion.

\section{Efficiency of Nozzles.}

It has been stated that the object of the nozzle is to change the heat energy of the steam into kinetic energy, and obviously it is of importance to know under what conditions this conversion will be most efficient. For the simple convergent nozzle the problem is comparatively easy, since that nozzle is only capable of expanding steam for some pressure $P$, say, to a lower pressure equal to about half of P. We have, therefore, to decide whether the nozzle should be made to work with this-its full range of pressure -or whether the back pressure should have some higher value. It may be mentioned that there is a general idea abroad that small pressure drops are conducive to efficiency, or, in other words, that so far as the nozzle is concerned, the nearer the back pressure is to the initial pressure the greater will be the nozzle efficiency. Actual nozzle experiments do not, however, support this contention, and as this point is important in its relationship to turbine design, it may be worth while to spend some little time in discussing it.

In Fig. 6 there are a number of curves which show the performances of a number of nozzles with fixed initial and varying back pressures. The coefficients of discharge are shown under these conditions, and, for the moment, this coefficient may be taken as proportional to the efficiency. It will be noticed that, in every case, the efficiency is greatest when the nozzle is working at its maximum pressure range. These results have been criticised on several occasions, but no experimental evidence has ever been brought forward to show that they do not give a true representation of what is taking place. It appears to be the case that preconceived ideas-due probably to a lack of appreciation of what exactly takes place in a nozzle-rather than scientific investigation, is the cause of the criticism of the results shown in Fig. 6. In support of this statement I would 
mention that the very large number of experiments carried out in the Royal Technical College, Glasgow, have consistently shown results similar to those given in the figure, and that it appears to be quite certain that maximum efficiency is always associated with maximum pressure drop. To illustrate further this point, an efficiencv curve, obtained by Mr. D. Anderson from a nozzle of rectangular section, is shown in Fig. 7. The increase in efficiency with increased pressure range is shown here quite clearly. The importance of a proper appreciation of this point may be better realised by an examination of Fig. 8, where the curves are drawn to a base of steam speed instead of pressure range. With maximum speed - which corresponds to maximum pressure drop-the efficiency is again shown to be at its highest. The top curve-one of velocity coefficients-is, however, a curve sometimes used in actual design offices and drawn on the assumption that the efficiency diminishes with increasing steam speed. How incorrect will be the calculations made by using this curve, instead of the lower, experimental one can be readily appreciated.

This statement will be, however, more convincing if I can bring forward evidence to show that the losses in a nozzle are such that it is inevitable that maximum efficiency will be associated with maximum pressure drop. In connection with the search tube measurements and the determination of the quantity of steam passing, a method of analysis has been developed by my colleague, Mr. W. Kerr, and myself which allows us to estimate the losses all along the nozzle. The method is rather involved, and I do not propose to go into it, but would rather direct attention to Fig. 8, where the losses along a particular nozzle may be seen. The top curve, showing the total loss, is one of great interest. It will be seen that at the inlet the loss first increases rapidly and then follow's a practically straight line law to the point of exit. Detailed examination shows that this total loss can be divided into two main portionsone a loss at entrance called the convergence loss, and the other a loss principally in the tail of the nozze due to frictional resistance. The convergence loss has been shown to vary with the speed and the frictional loss with the square of the speed. The presence of this convergence loss explains why the steam must have its maximum pressure drop if the nozzle is required to work at its highest efficiency.

Members may have noticed recent articles dealing with what is known as the super-saturated condition of steam in nozzle flow. According to the ordinary idea dry, saturated steam expanding with isentropic pressure drop 
in a nozzle ought to be partially condensed as the pressure is lowered. It is now considered that this condensation does not take place and that, due to the rapidity of the action, the steam expands for the greater part as an undercooled gas. This fact is mentioned in order to afford an opportunity for explaining that, in all the experiments described this evening, superheated steam was used of such a temperature that, even at the lowest nozzle pressure, the saturation state would not be reached. By this precaution any ambiguity in the results due to uncertainty of the steam condition has been avoided.

This concludes all I propose to say upon this important subject. I hope that I have been able to interest the members in the record of the work we are doing and that they will feel that these experiments, although they may appear to be of scientific interest only, are really fundamental to the correct designing of steam turbines.

\section{DISCUSSION.}

The Chairman: There is no doubt about it that the turbine, consequent upon the investigations made by Dr. Mellanby and others, has now become a very efficient machine for motive power, and I should like to see the use of it extended to the purposes of driving a locomotive. So far as the actual unit of power is concerned, I do not think there is so very much difficulty about that; but its application to the locomotive, in view of the adverse conditions, make it, I think, somewhat difficult. I do believe that in Switzerland they have turned out a turbine locomotive, but with what degree of success I am not able to say. As I said before, I should like to see it introduced, because I think it would be very much of a half-way step between the ordinary form of steam locomotive we have to-day and the electrification of railways. Two of the main difficulties that seem to be uppermost in my mind are-first, the question of condensing. Without that I do not think it could be a profitable machine. The second has reference to the rough shocks that the locomotive is apt to sustain when travelling over the rails.

I think we have all enjoyed Dr. Mellanby's discourse, and I am sure I am voicing the wishes of everyone in expressing to him our very best thanks for his kindness in coming here and reading us such an interesting Paper.

There are two of Dr. Mellanby's confrères here who would like to say something on the subject, and I would first call upon Mr. Kerr to address you. 
Mr. W. Kerr: Professor Mellanby's treatment of his subject does not afford much opportunity for criticism; his ,explanations of the various phenomena are too completely supported by the experimental facts. But while one is thus debarred from dealing critically with the matter of this interesting Paper, it might still be objected that the form of a general review of nozzle phenomena tends to hide the several points of particular importance. I may, therefore, be permitted to extract and emphasise one or two such points.

In his opening remarks Professor Mellanby referred briefly to the turbo-locomotive; and this is a matter which must be of great interest to the locomotive engineer. No one would, of course, suggest that the present type of reciprocating engine should be replaced by a steam turbine working on the same pressure range; but if a practicable solution of the condenser difficulty in locomotive work should be achieved, the turbine form of prime mover at once enters the lists. Under high back pressure conditions the turbine is less efficient than the steam engine, but when once a moderate vacuum has been reached the turbine drive surpasses the older type. Naturally, of course, the difficulties in the path of such developments are not small; the constructional problems involved in a combined turbine and condenser outfit for a locomotive are many, but by no means unsurmountable; and already there are signs that the condenser difficulty can be overcome.

When the obstacles in a particular line of progress seem overwhelming it is a good idea to stimulate the energy of attack by pondering the advantages that will accompany a solution. Thus, suppose we take dry steam at $180 \mathrm{lbs}$. per sq. in. abs. expanding to an exhaust pressure of $30 \mathrm{lbs}$. per sq. in. abs., the heat made available for transformation into work amounts to about $\mathrm{r}_{3} 6 \mathrm{~B}$.Th.U. per $1 \mathrm{~b}$. steam ; but if we lower the back pressure successively to I9 lbs. abs., Ioins. vac., Igins. vac., 24 ins. vac., this heat value is increased regularly in 25 per cent. increments. That is, at 24 ins. vac. the heat drop is twice the value at zolbs. abs. Now, at the vacuum condition the turbine will have at least as good a thermal efficiency as the engine has at the pressure condition, and hence the consumption rate might be reduced to half its present value, even allowing that a moderate vacuum is the best that can be expected.

It is obvious, therefore, that the successful condenser is something to strive after, and with its advent the turbine drive must receive most careful consideration. Then the 
facts that Professor Mellanby has so clearly explained become at once of value, since nozzle expansion is a fundamental point in turbine operations; and an appreciation of the characteristics of nozzles is essential to a proper understanding of the turbine. Thus, to take one point of some importance, viz., efficiency of expansion, Professor Mellanby's Fig. 6 gives the general form of the efficiency curve, which is rather remarkable in that there appears to be one particular range of expansion which gives the best results. This is the "critical range" for a convergent nozzle, and the convergent nozzle is the form usually employed in practice. The matter is a controversial one in turbine theory, but it has an important incidence in design; it really indicates a certain upper limit to the number of stages that should be fitted. That this limit is not thoroughly appreciated in turbine work is shown by the wide variety of designs; but it may be hoped that the facts presented by Professor Mellanby will be duly considered when the locomotive turbine is developed.

To turn to another point of some interest, the essential feature of which is also contained in this Paper, if examination is made of Professor Mellanby's curves of pressure of different nozzles it will be noticed that the jet pressure just beyond the nozzle outlet falls below the back pressure, under which the nozzle is operating. At high back pressures the "dip" is barely noticeable, but at low pressures it is very conspicuous. Now the "injector principle" is that a high speed jet can entrain and carry off fluid from the surrounding atmosphere. The locomotive itself usually contains two pieces of plant that work on the injector principle, viz., the boiler feed injector and the blast pipe, although the action in the former is greatly intensified by the condensation which ensues. The main point here is, however, that these simple pressure curves show at once how the entrainment takes place; the characteristic " dip" " in the pressure curve at outlet means that the jet is able to draw in the surrounding fluid by reason of its lower pressure, and that lower pressure as measured at the jet centre shows that the entrainment must be general throughout the body of the jet, and not merely a surface effect.

These few points on which I have remarked should serve at least to indicate that the apparently abstract subject of nozzle flow is by no means outside the scope of locomotive engineering ; and since in the process of development attention must ultimately be given to the steam turbine in its application to the locomotive, it should be satisfactory to know that, by the kindness of Professor 
Mellanby, the Proceedings of the Institution will now contain some of the important and up-to-date information on an essential turbine element.

Mr. D. S. Anderson: There are probably few subjects of such great experimental and theoretical difficulty as the flow of steam through nozzles. From a general point of view, it seems an exceedingly simple operation, but in reality it is extremely complex. Dr. Mellanby's exposition of the various phenomena of the subject is so lucid that it is apt to give one the impression that the results which he has shown us have been easily obtained. Such, however, is not the case. Only those who have followed out this, or some allied line of research, have any idea as to the enormous amount of time which has to be spent in calculations to work up a few experimental facts. Considering, then, the labour involved, both in the experimental and the theoretical investigations, our indebtedness to Dr. Mellanby in so freely placing his knowledge at our disposal is all the greater.

The illustrations in the Paper all show phenomena connected with round nozzles. This is the ideal type of nozzle, considering it as a nozzle alone, and it is also the most suitable type for a fundamental investigation; but considering it as a unit of a turbine, it is no longer ideal. In a turbine we have a series of rectangular blade passages passing in front of a series of nozzles delivering high speed jets. If the nozzles are round in form, then the jet will also be round, but a round jet will not fill all the rectangular passages crossing its path. Some of the passages will only be partially filled, and those partially filled passages are a source of loss. The loss due to this is greater than the gain due to the use of a round nozzle in place of a rectangular one; hence all modern turbines are fitted with rectangular nozzles.

The phenomena of both round and rectangular nozzles are fundamentally the same. Fig. 9 shows the pressure ratio curves for a square convergent parallel nozzle. Two sets of curves are shown; one set was taken with the hole in the search tube pointing to the middle of a side, and the other with the search tube hole pointing to a corner. It will be noted that, though there are differences between those curves and the round nozzle curves already shown, the general form is the same. The fact that two different sets of pressure ratio curves can be obtained from this nozzle shows clearly the complex nature of the expansion. The loss in a nozzle with a complex expansion of this kind is naturally more severe than in a round one, where the fall 
of pressure is uniform in all directions along the nozzle. This type of expansion is due to the unsymmetrical nature of the nozzle form. The round nozzle has the more perfect entry and tail, and consequently the simpler expansion.

Dr. Mellanby has spoken of a portion of the loss in a nozzle being due to friction. Such a loss is, of course, influenced by the nature of the nozzle surface. The effect of this can be quite clearly detected in the pressure ratio curves. Fig. Io shows two sets of pressure ratio curves -one set taken from a nozzle with a polished surface and the other from the same nozzle after it had been roughened all over by scoring with a file. It will be seen how the form of the curve has altered. With roughening, the throat pressure has been raised and the outlet pressure lowered. The lowering of the outlet is capable of a very simple explanation. It has been already stated in the Paper that the limiting velocity, to which a nozzle of the convergent parallel type can expand, is the velocity of sound in the medium at the outlet conditions. In the perfect nozzle this velocity is developed with an expansion down to a pressure ratio of .546 ; in other words, the energy liberated in the expansion down to this pressure ratio is sufficient to generate in the fluid a speed equal to the speed of sound. Any ordinary expansion is more or less imperfect. Losses occur, and these losses absorb some of the liberated energy. That being so, all the energy does not go to create onward velocity, and the limiting speed of sound will not be reached at the ratio .546 . Further expansion, therefore, takes place until the fluid does acquire this limiting velocity. The extra expansion necessary will be greater, the greater the losses. This is well exemplified in the two curves shown. The full range expansion with polished surface has an outlet pressure ratio of .49 (theoretical .545), while in the roughened nozzle this ratio falls to .44 .

I think there is only one other point which I might montion, and that is the measurement of pressure in nozzles with a curved axis. Naturally, the search tube cannot be used in this case. The difficulty has been successfully overcome in this manner. A flat-bottomed hole is bored in one of the walls enclosing the nozzle passage. This hole does not penetrate into the steam space, but leaves a thin wall, say about $1 /$ I 6 in. thick. The hole itself may be $\frac{1}{8}$ in. dia. The thin wall is then bored through with a drill $1 / 32$ in. dia. at the point at which the pressure is wanted. A copper pipe $\frac{1}{8}$ in. dia. is screwed or silver soldered into the hole and then suitably connected to a gauge. By this means 
the pressure at any point can be determined without interfering with the flow.

In conclusion, I might say that Dr. Mellanby's Paper will be a very valuable contribution to the Proceedings, giving, as it does, the most recent developments in the extraordinarily difficult subject of nozzle flow.

Mr. M. Blacklock (Messrs. W. Beardmore and Co., Dalmuir): We are in rather an academic atmosphere, which, though unusual, is yet very charming. It has been a great pleasure to listen to this Paper by Dr. Mellanby, supplemented by the remarks of Mr. Kerr and Mr. Anderson, and it is a valuable contribution to the Proceedings of the Institution. It is rather interesting to learn that there are such marked differences of opinion amongst turbine designers as to the best pressure drop for maximum nozzle efficiency. I have not studied the matter at all, but have had a vague notion that a high pressure range was essential in a turbine. Thus one is interested to hear that in some drawing offices an opposite opinion is held.

From any steam table one may gather that for maximum overall efficiency it is necessary to expand down to a very low pressure-a greater gain results from a given drop at a relatively low pressure than from the same drop at a higher pressure. I think we all recognise quite well that the efficiency of the low pressure steam turbine is very much higher than that of the ordinary steam locomotive, and all locomotive engineers would be delighted if it were found practicable to adapt the turbine to locomotive driving. But, as the Chairman has already said, there are great difficulties in the way. One may decide, in principle, the various elements necessary, but there arises the "special " difficulty - the finding of a convenient position for all the mechanism that is required.

We have to get a highly efficient condenser and a highly efficient turbine. There is then the problem of transferring the high efficiency at the turbine shaft to the rim of the driving wheels of the locomotive, and that is a real difficulty. One's mind inevitably turns to the application of the electric drive, but that results in a most complicated and expensive machine, the interest and standing charges on which go far to counteract the great thermodynamic advantages derived from it. A number of experimental engines have been built both at home and abroad; one, indeed, is said to be undergoing trials on a home railway to-day, and the results will be interesting reading. Another example can be found quite close to where we now are. 
These two that I have mentioned transform the efficiency of the turbine into mechanical energy at the rail by electric transmission, but $\mathrm{I}$ believe that the one in Switzerland, to which the Chairman has referred, has a direct drive. The turbine is placed in front of the smokebox of what looks like an ordinary locomotive, and by reduction gear drives a jack shaft, and the power is then transmitted from the jack shaft to the driving wheels by coupling rods.

One of the accessories to any turbine locomotive is a condenser, to give a vacuum of about 28 inches; but there is not room for that on the engine. It is sometimes carried on a separate vehicle, or tender, and it is also necessary to carry about as much water for cooling purposes as is equal to the water actually evaporated in the boiler. But as the steam consumption is low the water required for cooling is much less than the amount which has to be carried as boiler feed on the ordinary steam locomotive. If it were possible to take the ordinary reciprocating steam locomotive as we know it, get from it the work it does to-day, and then apply to it a low pressure turbine, it would obviously be a very fine thing. But we cannot recapture the steam after it has passed the blast pipe, and are obliged to think in terms of compounding where the locomotive would exhaust, not as at present into the atmosphere with a back pressure of io to $20 \mathrm{lbs}$., but into a receiver with a back pressure of 50 to 70 lbs., as is usual in a purely compound locomotive. In such an application the research work we have heard about might be very helpful. We are out of our depth with these trials, and want someone to do our thinking for us.

Will Dr. Mellanby answer just one question? Locomotive steam ports are often made with a sudden change of section, and it is said that very great eddv losses take place because of that. What is the nature of eddy losses in general, and what becomes of the energy which the steam is said to give out in passing through the suddenly changing section of a steam port-where does it go to?

The Author: I must thank you for the consideration with which you have listened to my remarks, and I must also acknowledge my indebtedness to the various speakers for the kind things they have said about the Paper. The figures presented by Mr. Kerr show, in a very convincing fashion, the economic advantages to be expected if the turbine were applied to locomotive practice. It should be especially noted that, even with the low vacuum of 24 inches, the consumption might be reduced to about half its present 
amount. Mr. Kerr's point relating to the power of the nozzle to draw air into a steam jet is also one worth considering. It seems quite probable that a proper appreciation of the pressure fall in a nozzle would lead to a considerable improvement in the design of locomotive blast pipes. It is possible at the present moment, when there is so much steam available for blast purposes, that this is of no great moment, but if the greater part of the steam could be utilised to do work at pressures below atmospheric, greater efficiency in blast pipes would be worth striving for.

Mr. Anderson's remarks upon the effect of surface friction in nozzles are of great interest, and his explanation of the reduction in the nozzle outlet pressure with increased roughness of surface is very convincing. Although it has long been known that smooth nozzles gave better results than rough ones, so far as I know, the experiments of $\mathrm{Mr}$. Anderson are the first to give actual quantitative results. His experiments with nozzles of rectangular section are also of importance, and the search tube readings showing the complex nature of the expansion in nozzles of this type disclose features which appear to have been unsuspected by previous investigators. His own experiments have brought home to him the tremendous amount of arithmetic involved in working out even an experiment; but I should like to take this opportunity of admitting that most of the laborious work involved in the preparation of the lecture I have just given was carried out by Mr. Kerr.

Some of Mr. Blacklock's questions have been answered in Mr. Kerr's contribution to the discussion, but it is worth mentioning again that a prime mover working under even moderate vacuum conditions would result in a great gain in economy. There is no doubt that there are great practical difficulties to be overcome before the turbine can be applied successfully to the locomotive, and what the final arrangement will be it is impossible to predict. Mr. Blacklock has pointed out that the two great problems are those involved in the design of a successful condenser and the transmission of the power developed in the turbine to the driving wheels. The condenser problem is, however, one that seems amenable to scientific treatment, and Mr. Blacklock will be interested to learn that investigations, which have for their object the successful design of this part of a locomotive plant, are now being carried on in the College. The power transmission problem is rendered difficult by the great speed changes to which the locomotive is subject. With a reciprocating engine there is no great variation in efficiency with change of speed, but with the turbine, unfor- 
tunately, this happy state of affairs does not exist. Many: of the difficulties associated with this part of the problem. would be solved by the introduction of the electric drive; but so many other points are raised by this arrangement that it would be inadvisable to go into them at present. The combination of reciprocating engine with low pressure. turbine is one to which I have devoted a considerable amount of attention, and Mr. Blacklock will be pleased to learn that, in conjunction with one of the local firms, it is being fully investigated. The point raised about the steam ports leads to the statement that if steam ports were designed more carefully, with the steam nozzle as a basis, wire-drawing losses could be considerably reduced. This has been appreciated by several of the successful manufacturers of internal combustion engines, who are making. two-stroke cycle engines, where the exhaust gases and inlet air have to pass through ports in the cylinder walls. By varying the shape of these ports they have been able to obtain appreciably increased economy. The friction and eddy losses in a nozzle result in the production of heat, with the result that steam discharging from a badly-designed nozzle carries away into the exhaust, say, a quantity of heat which otherwise might have gone to increase the kinetic energy of the jet. In the steam port the bad design will have the objectionable result of raising the back pressure, and the steam, on reaching the atmosphere, will have additional heat in it, representing the amount of work that has been necessary to force it out against the unnecessary resistance.

The Chairman did not raise any points that require to be dealt with, but I take this opportunity of thanking him for his appeciative remarks. 


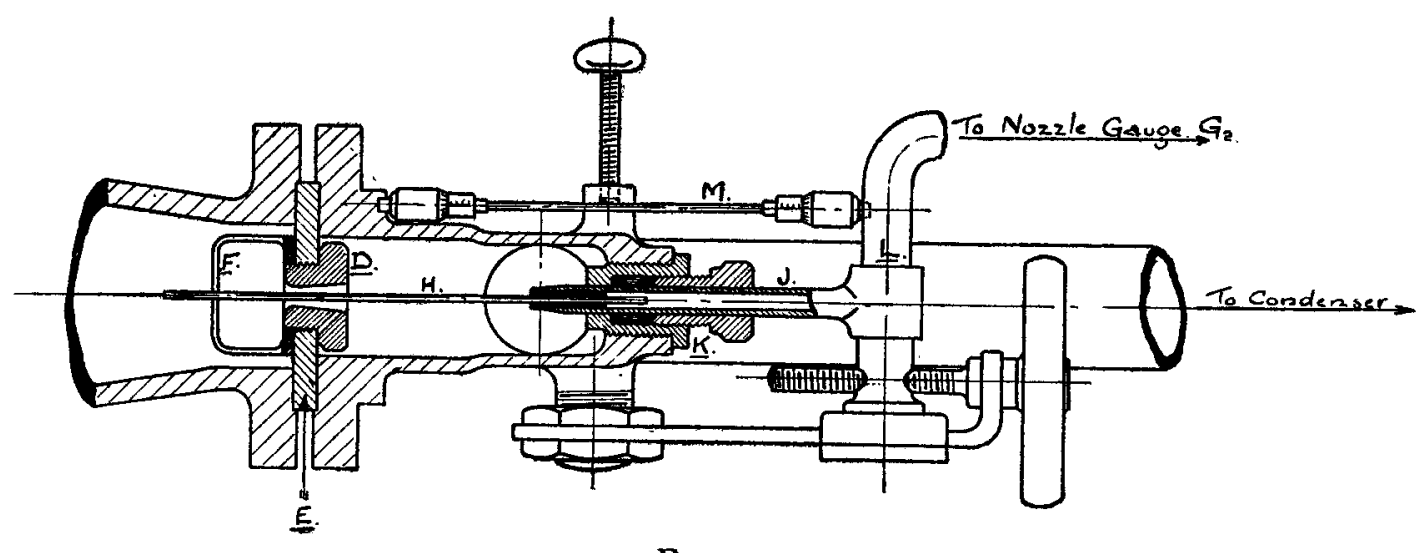

Fia. 1 . 


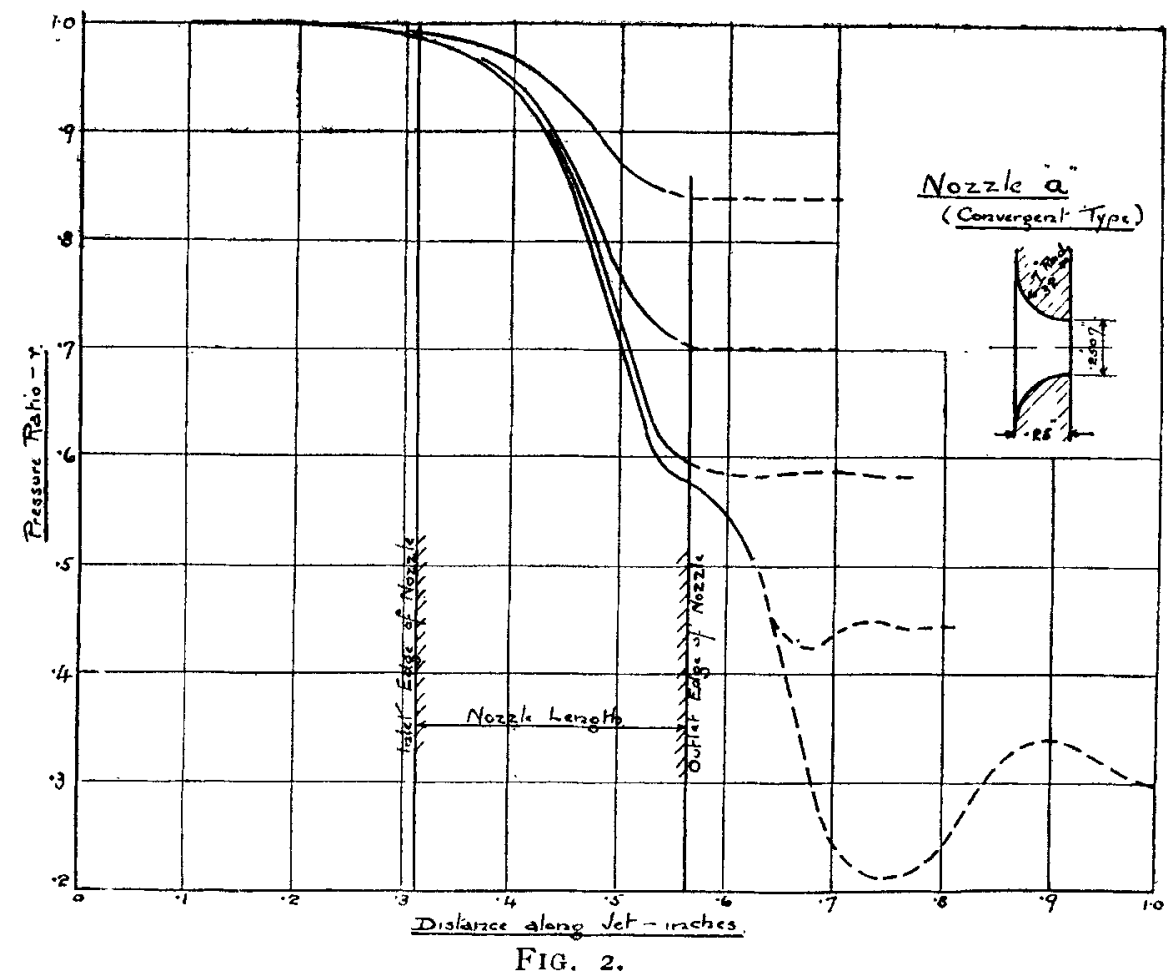




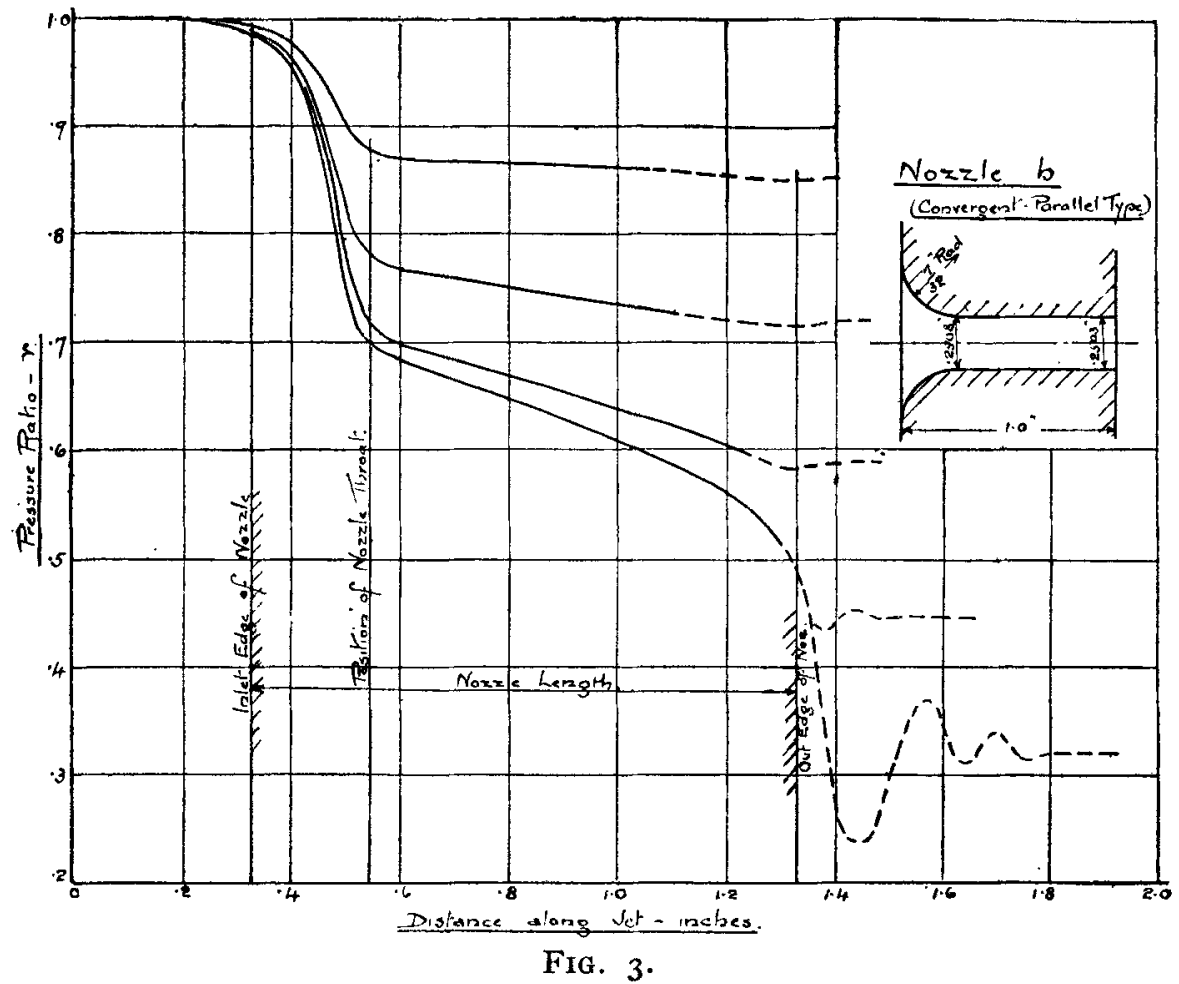




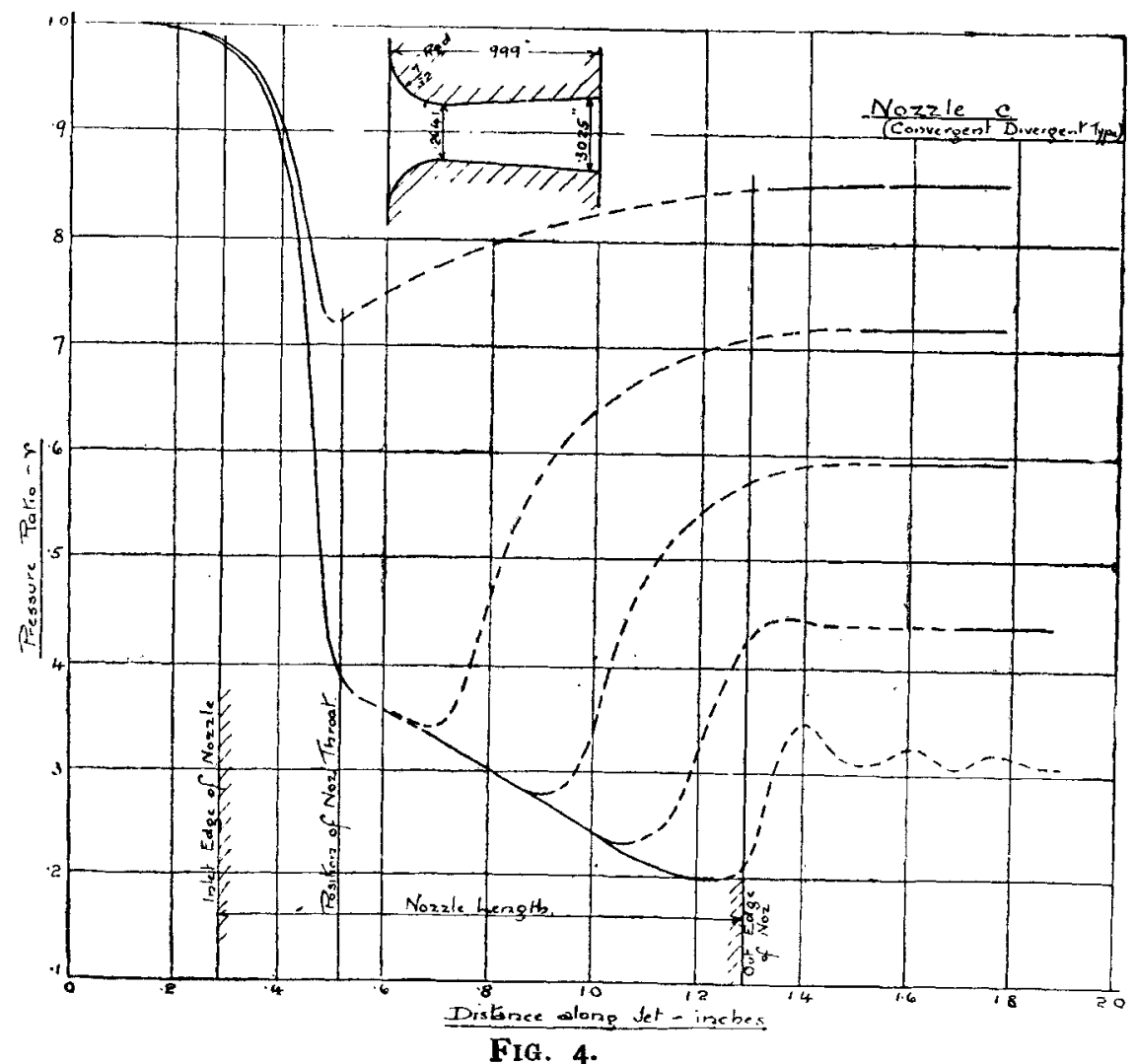

용 
FLOW OF STEAM THROUGH NOZZLES-MELLANBY. $\quad \mathbf{5 6}^{6}$

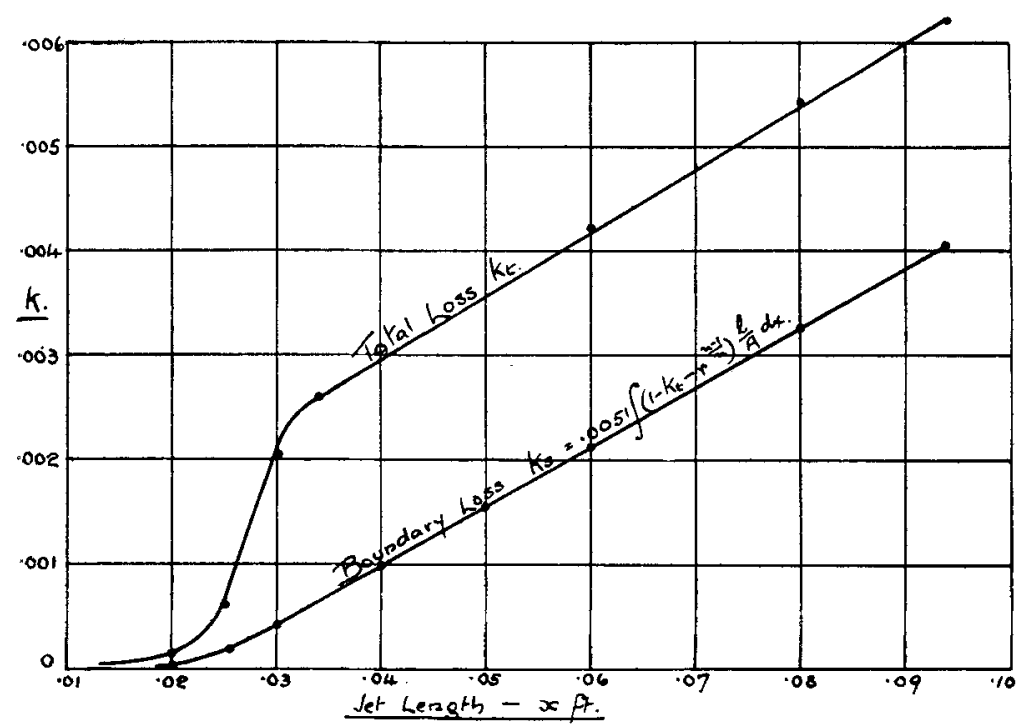

FIG. 5.

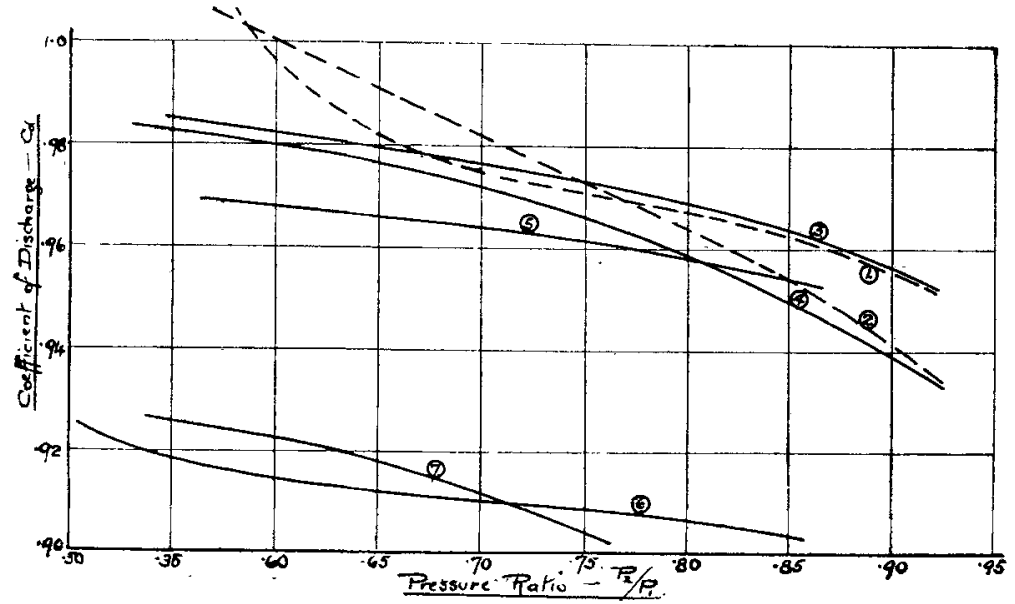

Fig. 6. 


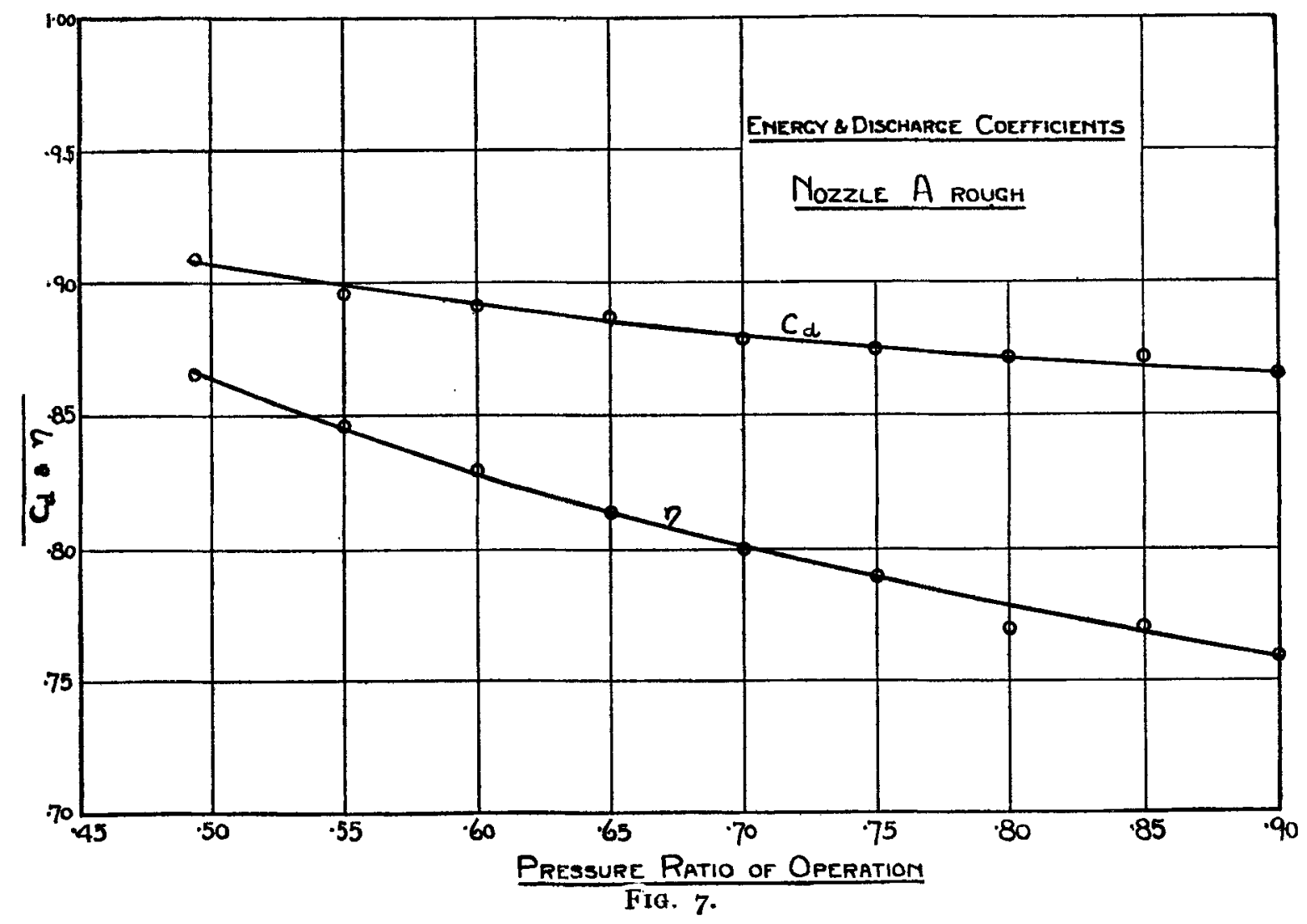




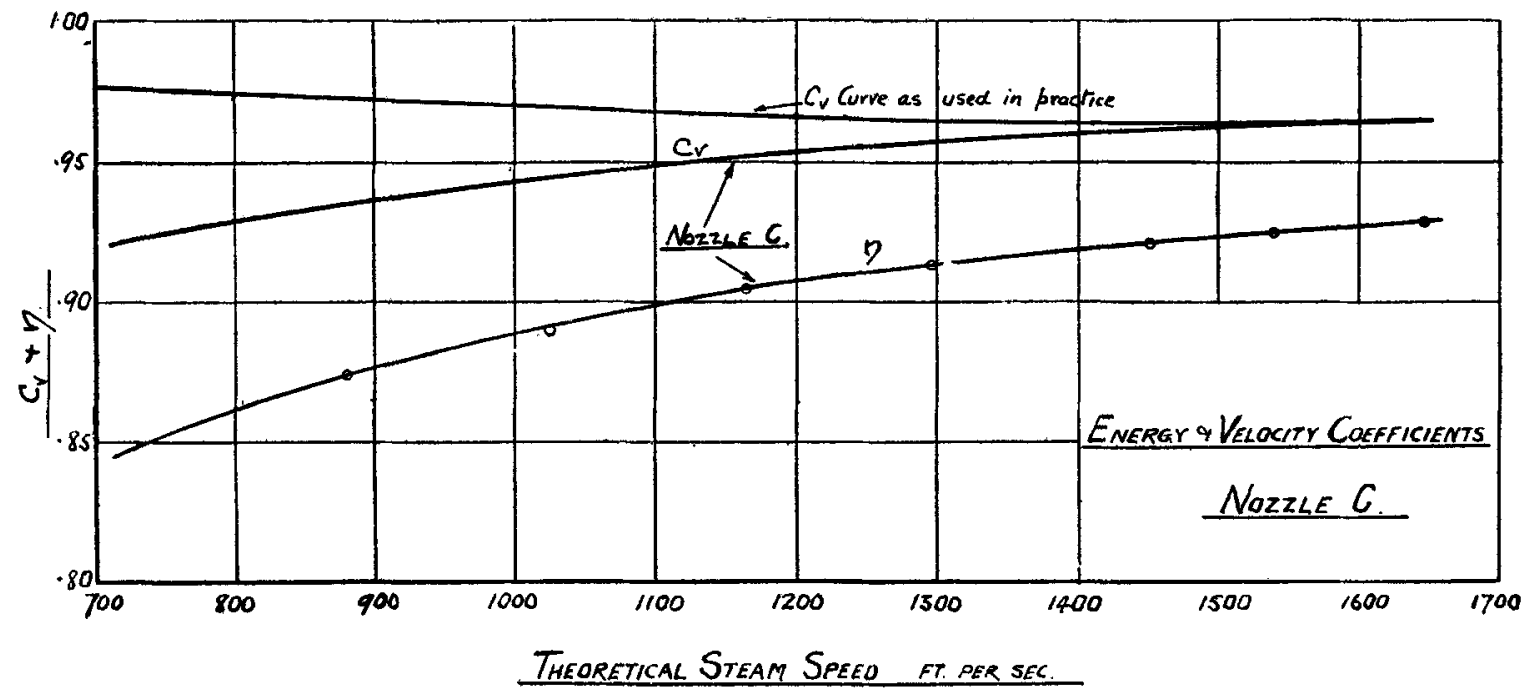

Fig. 8. 


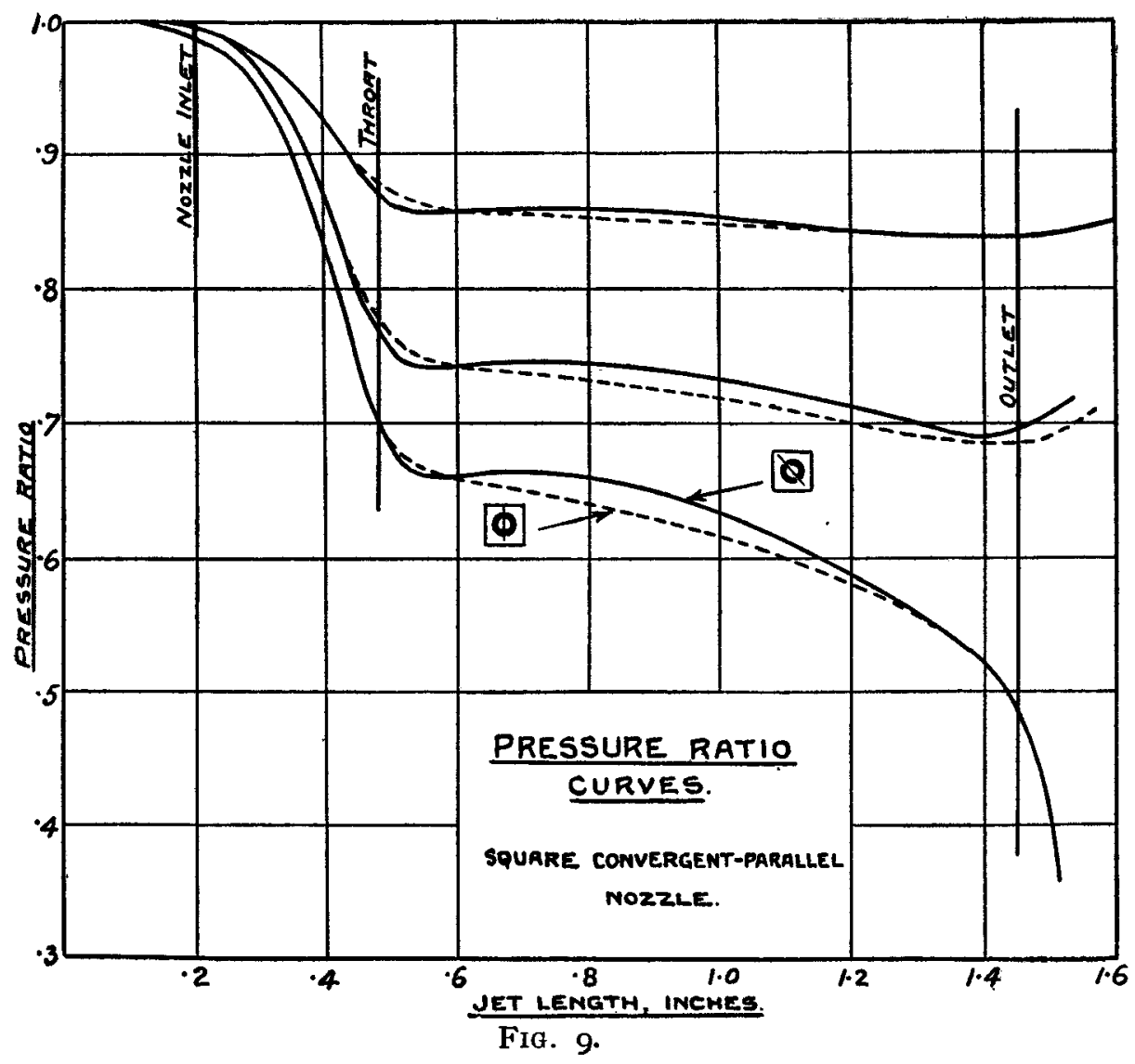




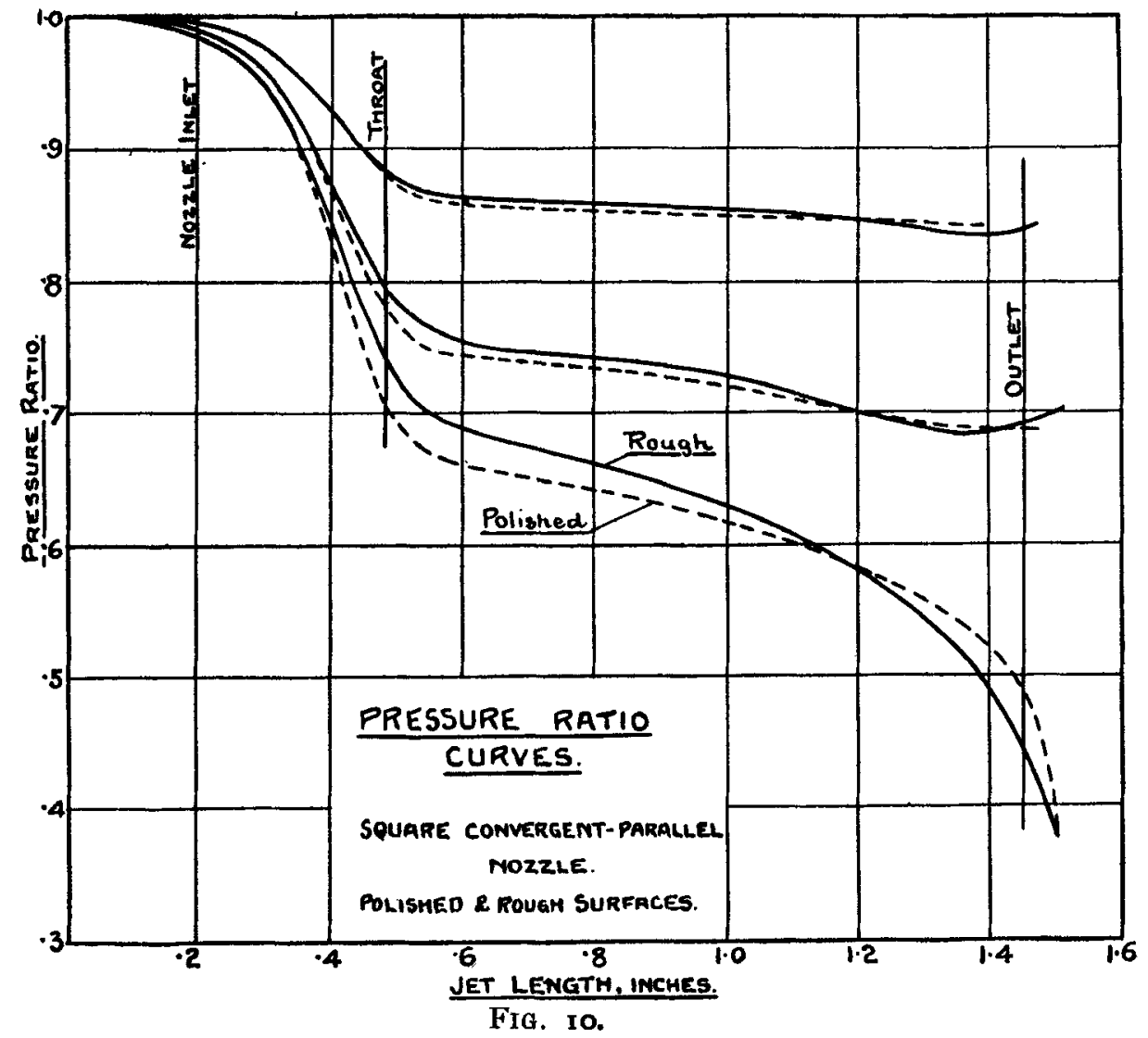

